\title{
Laxative effects of agarwood on low-fiber diet-induced constipation in rats
}

\author{
Mamoru Kakino', Shigemi Tazawa², Hiroe Maruyama², Kazuhiro Tsuruma', Yoko Araki², \\ Masamitsu Shimazawa', Hideaki Hara ${ }^{1 *}$
}

\begin{abstract}
Background: Agarwood (Aquilaria sinensis), well known as incense in Southeast Asia, has been used as a digestive in traditional medicine. We investigated the laxative effects of an ethanol extract of agarwood leaves (EEA) in a rat model of low-fiber diet-induced constipation.

Methods: A set of rats was bred on a normal diet while another set was placed on a low-fiber diet to induce constipation. The laxative effect of agarwood was then investigated on both sets of rats.

Results: Pretreatment of normal rats with single dose of EEA (600 mg/kg, p.o.) significantly increased frequency and weight of stools. Also, treatments with EEA (300 and $600 \mathrm{mg} / \mathrm{kg}$, p.o.) for 14 days caused a significant increase in stool frequency and weight. Feeding of the animals with a low-fiber diet resulted in a decrease in stool weight, frequency, and water content and also delayed carmine egestion. A single treatment with EEA $(600 \mathrm{mg} / \mathrm{kg})$ or senna (150 and $300 \mathrm{mg} / \mathrm{kg}$ ) significantly increased stool frequency, weight, and water content and also accelerated carmine egestion in the model rats. Once daily administrations of EEA $(150 \mathrm{mg} / \mathrm{kg})$, for 14 days, caused a significant increase in water content of stools. The higher doses of EEA (300 and $600 \mathrm{mg} / \mathrm{kg}$ ) significantly increased frequency, weight, and water content of the stools while accelerating carmine egestion in the constipated rats. Senna (150 and $300 \mathrm{mg} / \mathrm{kg}$ ) produced similar effect as the higher doses of EEA but, in addition, induced severe diarrhea.
\end{abstract}

Conclusion: These findings indicate that EEA has a laxative effect, without causing diarrhea, in a rat model of lowfiber diet-induced constipation. These findings suggest that EEA may be highly effective on constipation as a complementary medicine in humans suffering from life style-induced constipation.

\section{Background}

Constipation is a common public health problem with a well-recognized propensity to cause discomfort and to affect quality of life. Constipation increases during aging and can be a chronic condition requiring the use of laxatives over the long term. Constipation is not only discomforting but can also cause abdominal distension, vomiting, restlessness, gut obstruction, and perforation, and may be associated with aspiration or fatal pulmonary embolism [1]. At present, 20 to $30 \%$ of people over the age of 60 use a laxative more than once a week [2]. Drugs containing magnesium oxide or sennoside, the main constituent of senna, are typically administered for

\footnotetext{
* Correspondence: hidehara@gifu-pu.ac.jp

'Molecular Pharmacology, Department of Biofunctional Evaluation, Gifu

Pharmaceutical University, Gifu 501-1196, Japan

Full list of author information is available at the end of the article
}

treatment of constipation due to their powerful purgative/laxative activities, but these drugs also induce severe diarrhea as a side effect. In addition, repeated use of senna or other anthraquinoide-containing drugs can induce melanosis coli (colic melanosis), a risk factor for colorectal neoplasm [3]. Agarwood, also well known as incense in Southeast Asia, has been used as a sedative, analgesic, and digestive in traditional medicine. Agarwood leaves are consumed as a healthy tea in Thailand and Taiwan. However, the botanical name "Agarwood" in English applies to more than fifteen different species (Aquilaria apiculina, found in the Philippines; Aquilaria baillonil, found in Cambodia; Aquilaria baccarain, found in Indonesia; Aquilaria brachyantha, found in Malaysia; Aquilaria crasna, found in Thailand, Malaysia and Cambodia; Aquilaria sinensis, found in Taiwan, etc.). In our previous study, we demonstrated that 
Aquilaria sinensis and Aquilaria crasna have laxative effects on a mouse model of loperamide-induced constipation, without inducing diarrhea. Agarwood (Aquilaria sinensis) also accelerates gastrointestinal transit in loperamide-induced constipation mouse model and increases the spontaneous contractions of isolated guinea pig jejunum and ileum. The increased contractions and laxative effect of agarwood can be blocked by atropine, a muscarinic receptor antagonist [4].

Constipation arises from a variety of causes (e.g., chemical compounds such as morphine, dietary habits, and psychological stress, etc.). The mouse model of loperamide-induced constipation corresponds to morphine-induced constipation in human patients since both loperamide and morphine are opioid-receptor agonists. In the present study, we used a rat model of low-fiber diet-induced constipation, which has the same similarities as human patients suffering from constipation as a result of poor dietary habits. The purpose of the present study was to investigate the laxative effects of EEA using a rat model of low-fiber diet-induced constipation.

\section{Methods}

\section{Materials}

Agarwood (Aquilaria sinensis, gathered in Daisoukou, Taipei, Taiwan) and senna (Senna alexandrina) leaves were supplied by API Co., Ltd. (Gifu, Japan). The species of these botanical materials were authenticated by Professor Munekazu Iinuma Ph.D. (Pharmacognosy, Department of Bioactive Molecules, Gifu Pharmaceutical University). The voucher specimen of EEA (JLE-50P080924) was deposited at Nagara Research Center, API Co., Ltd. (692-3 Nagarayamasaki, Gifu 502-0071, Japan). Carmine was purchased from Wako Pure Chemical Co., Ltd. (Osaka, Japan).

\section{Extraction and isolation procedures}

Agarwood and senna leaves (each $50 \mathrm{~g}$ ) were chopped into smll pieces and extracted with $60 \%$ ethanol (1000 $\mathrm{ml})$ at room temperature $\left(25.0^{\circ} \mathrm{C}\right)$ for $24 \mathrm{~h}$. We got 8.0 $9.0 \mathrm{~g}$ of solid powder from each leaves every time.

\section{Animals}

Male SD rats (6 weeks old) were purchased from Japan SLC (Hamamatsu, Japan). The animals were housed at a controlled room temperature $\left(24.5-25.0^{\circ} \mathrm{C}\right)$ with a $12 / 12$ $\mathrm{h}$ light/dark cycle. Food pellets (CE-2, CREA Japan, Inc., Tokyo, Japan) and tap water were provided ad libitum. All animal experiments were carried out according to the "Principles of Laboratory Animal Care" (NIH publication number 85-23, revised 1985) and "Guidelines of the Animal Investigation Committee of Gifu Pharmaceutical University".

\section{Ethical approval}

All experiments were approved by the Animal investigation Committee of Gifu Pharmacological University.

\section{Stool parameters}

The frequency and weight of stools were measured as the frequency and total wet weight per rat over $16 \mathrm{~h}$ (Figure 1C). EEA (150, 300, and $600 \mathrm{mg} / \mathrm{kg}$ ) and senna (150 and $300 \mathrm{mg} / \mathrm{kg}$ ) were orally administered once daily for 14 days (Figure 1A). Gum arabic (5\% w/w) was orally administrated as a vehicle. Carmine (10 mg/body) was administered via the same route immediately after sample administration. The frequency, weight, and water content of stools from each rat were measured at $2 \mathrm{~h}$ intervals for 16 hours (e.g. 0-2 h, 2-4 h, 4-6 h, etc.). Carmine egestion by each rat was measured at $2 \mathrm{~h}$ intervals for $24 \mathrm{~h}$. Rats were then placed individually in stainless steel cage $(24 \times 38 \times 20 \mathrm{~cm})$ and fasted for $8 \mathrm{~h}$ but provided with water ad libitum.

\section{Induction and evaluation of constipation}

Rats were maintained on a low-fiber diet for 5 weeks to induce constipation prior to the experiments (Figure 1B). The low-fiber diet (Crea Japan, Inc.) contained $41.5 \%$ cornstarch, $24.5 \%$ milk casein, $10.0 \%$ sucrose, $10.0 \%$ dextrin, $7.0 \%$ mineral mixture, $6.0 \%$ corn oil, and $1.0 \%$ vitamin mixture (Table 1 ). Induction of constipation were evaluated by stool parameters (frequency, weight, water contents, and carmine egestion).

\section{Statistical analysis}

Data are presented as mean \pm S.E.M. Statistical comparisons were made with the Student's $t$-test, Tukey's multiple comparison test, or $\mathrm{x}^{2}$ test (JSTAT for Windows; Vector, Tokyo, Japan).

\section{Results}

\section{Laxative effects of EEA and senna in normal rats}

To examine the laxative effects of EEA on frequency and wet weight of stools in normal male rats, EEA (150, 300 , and $600 \mathrm{mg} / \mathrm{kg}$ ) and gum arabic (as a control) were orally administered once daily for 14 days (Figure 1A). The frequency and the wet weight of stools were measured on the first day and again on the $14^{\text {th }}$ day (Figure $1 \mathrm{C})$. The frequency and the wet weight of stools following a single administration of gum arabic were $22.2 \pm$ 4.97 and $5.74 \pm 1.70 \mathrm{~g}$, respectively (Figure $2 \mathrm{~A}$ and $2 \mathrm{C}$ ). A single administration of EEA at $600 \mathrm{mg} / \mathrm{kg}$ significantly increased the frequency and wet weight of stools to $31.5 \pm 4.25$ and $8.29 \pm 1.21$ g, respectively (Figure 2A and $2 \mathrm{C}$ ). A single administration of EEA at 150 and 300 $\mathrm{mg} / \mathrm{kg}$ showed tendency to increase the frequency and wet weight of stools, but the increment was not statistically significant (Figure $2 \mathrm{~A}$ and $2 \mathrm{C}$ ). 

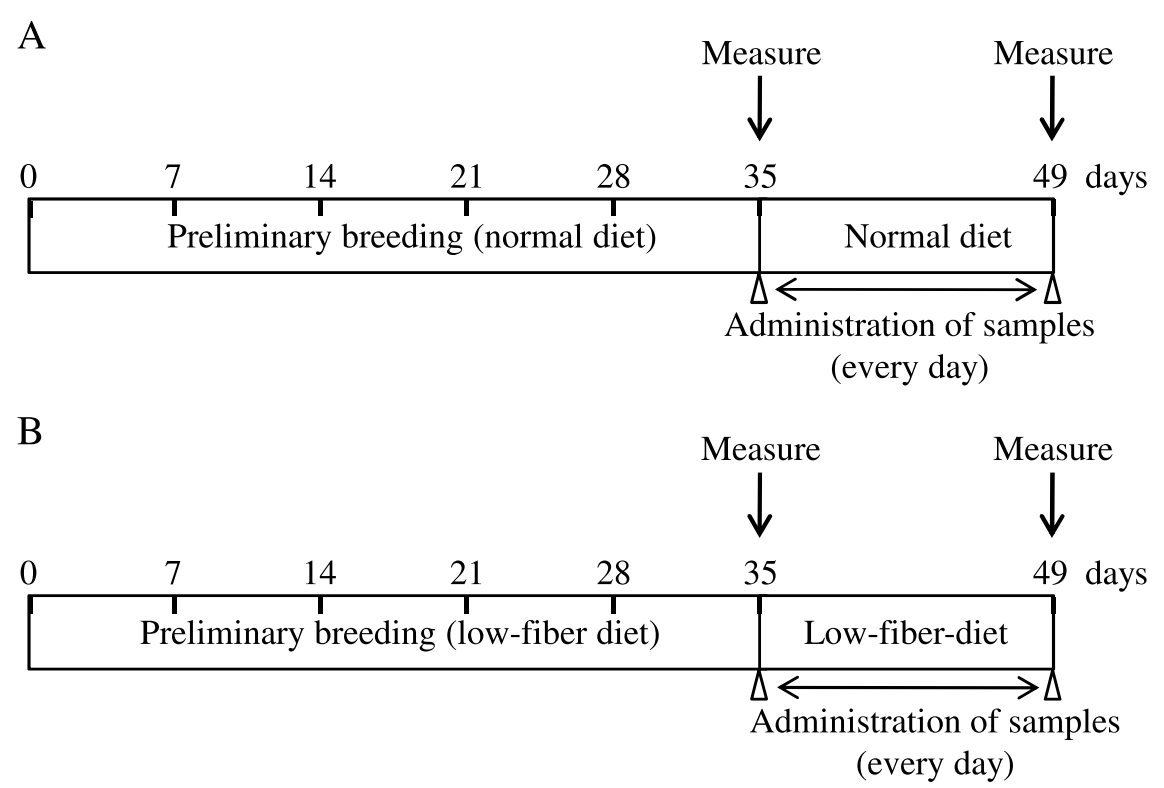

$\mathrm{C}$

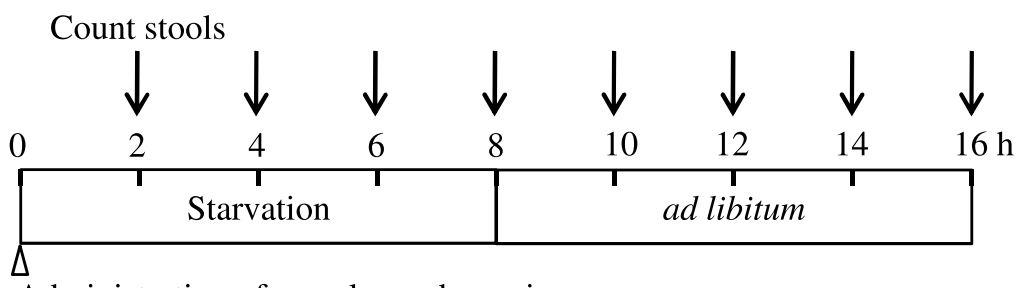

Administration of samples and carmine

Figure 1 The schedule of examination performed in this study.

The frequency and the wet weight of stools following multiple oral administrations of gum arabic for 14 days were $16.3 \pm 3.98$ and $4.79 \pm 1.14 \mathrm{~g}$, respectively (Figure $2 \mathrm{~B}$ and 2D). Multiple oral administrations of EEA for 14 days significantly increased the frequency and wet weight of stools to $20.8 \pm 2.98$ and $6.00 \pm 1.10 \mathrm{~g}$, respectively, at $300 \mathrm{mg} / \mathrm{kg}$ or to $25.5 \pm 5.42$ and $8.09 \pm 1.91 \mathrm{~g}$, respectively, at $600 \mathrm{mg} / \mathrm{kg}$ (Figure $2 \mathrm{~B}$ and $2 \mathrm{D}$ ). A single administration of EEA at $150 \mathrm{mg} / \mathrm{kg}$ showed a tendency

Table 1 Composition of the normal diet and low-fiber diet

\begin{tabular}{lcc}
\hline & \multicolumn{2}{c}{ contents (\%) } \\
\cline { 2 - 3 } Ingredients & normal diet & low-fiber diet \\
\hline Moisture & 9.3 & 9.0 \\
Crude protein & 25.1 & 21.9 \\
Crude fat & 4.8 & 6.1 \\
Crude fiber & 4.2 & 0.1 \\
Crude ash & 6.7 & 5.9 \\
NFE & 50.0 & 57.0 \\
\hline
\end{tabular}

NFE: Nitrogen Free Extract to increase the frequency and wet weight of stools, but the increment was not statistically significant (Figure 2B and 2D).

The effect of low-fiber diet on stool parameters

Before assessing the laxative effects of EEA and senna on low-fiber diet-induced constipation in rats, the effects of a 5 week treatment with a low-fiber diet were determined on the frequency, weight, and water content of stools. Rats were purchased at 6 weeks old and maintained on a normal diet (as a control) or on a low-fiber diet for 5 weeks. After 5 weeks of feeding, carmine (10 $\mathrm{mg}$ /body) was orally administered, then stool frequency, weight, and water content were measured (Figure 3A, B, and $3 C$ ) and carmine egestion was investigated in each rat during consecutive $2-\mathrm{h}$ periods for $16 \mathrm{~h}$ (Table 2 ). Stool frequency, weight, and water content of rats maintained on the normal diet were $22.3 \pm 1.15,5.31 \pm 0.25$ g, and $50.8 \pm 1.00 \%$, respectively (Figure $3 \mathrm{~A}, \mathrm{~B}$, and $3 \mathrm{C}$ ). Treatment for 5 weeks with a low-fiber diet significantly reduced the stool frequency, weight, and water content to $8.83 \pm 1.19,0.97 \pm 0.16 \mathrm{~g}$, and $39.7 \pm 1.92 \%$, 


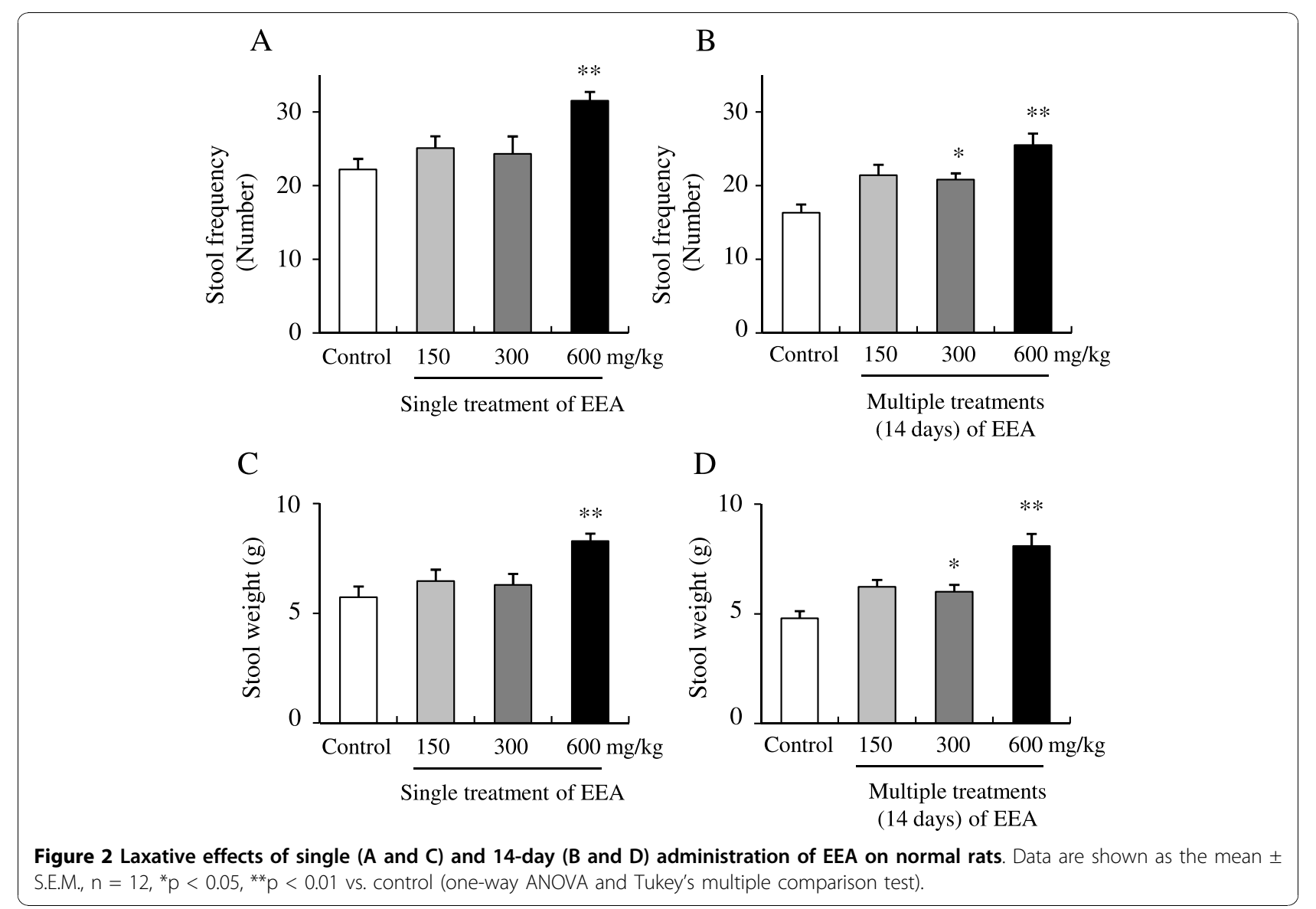

respectively, (Figure 3A, B, and 3C). The 5-week lowfiber diet also significantly delayed carmine egestion (Table 2).

\section{Effects of EEA and senna on stool parameters in the rat model of low-fiber diet-induced constipation}

To examine the effects of EEA and senna on stool frequency, weight, and water content and on carmine egestion in the low-fiber fed rats, constipation was induced in the rats by maintaining them on the low-fiber diet for 5 weeks. Then, EEA (150, 300, and $600 \mathrm{mg} / \mathrm{kg})$, senna (150 and $300 \mathrm{mg} / \mathrm{kg}$ ), and gum arabic (as a control) were orally administered once daily for 14 days according to the schedule shown (Figure 1B). Stool frequency, wet weight, and water content following a single administration of gum arabic were $5.70 \pm 2.74,0.70 \pm 0.40 \mathrm{~g}$, and $38.6 \pm 11.7 \%$, respectively (Figure $4 \mathrm{~A}, \mathrm{C}$, and $4 \mathrm{E}$ ). A single administration of EEA at $600 \mathrm{mg} / \mathrm{kg}$ significantly increased stool frequency, wet weight, and water content to $11.8 \pm 4.04,1.90 \pm 0.86 \mathrm{~g}$, and $50.9 \pm 8.9 \%$, respectively (Figure 4A, C, and 4E). A single administration of EEA at either 150 or $300 \mathrm{mg} / \mathrm{kg}$ did not affect stool frequency, wet weight, or water content (Figure 4A, C, and 4E).
A single administration of senna significantly increased stool frequency, wet weight, and water content to $19.8 \pm 3.76,4.6 \pm 1.28 \mathrm{~g}$, and $76.6 \pm 6.1 \%$ respectively, at $150 \mathrm{mg} / \mathrm{kg}$ and to $22.5 \pm 5.05,6.10 \pm 1.47 \mathrm{~g}$, and $81.8 \pm 4.70 \%$, respectively, at $300 \mathrm{mg} / \mathrm{kg}$ (Figure $4 \mathrm{~A}$, $\mathrm{C}$, and $4 \mathrm{E}$ ). A single administration of EEA at $600 \mathrm{mg} /$ $\mathrm{kg}$ and of senna at 150 and $300 \mathrm{mg} / \mathrm{kg}$ significantly accelerated carmine egestion (Table 3A). A single administration of senna at 150 or $300 \mathrm{mg} / \mathrm{kg}$ induced diarrhea in all the animals used (Table 4).

Stool frequency, wet weight, and water content following multiple oral administrations of gum arabic for 14 days were $3.75 \pm 2.53,0.57 \pm 0.42 \mathrm{~g}$, and $40.2 \pm 7.7 \%$, respectively (Figure 4B, D, and 4F). Multiple oral administrations of EEA for 14 days significantly increased stool frequency, wet weight, and water content to $9.7 \pm 4.3$, $1.73 \pm 0.79 \mathrm{~g}$, and $51.0 \pm 4.0 \%$, respectively, at $300 \mathrm{mg} /$ $\mathrm{kg}$ and to $10.3 \pm 3.4,1.98 \pm 0.73 \mathrm{~g}$, and $54.7 \pm 7.0 \%$, respectively, at $600 \mathrm{mg} / \mathrm{kg}$ (Figure 4B, D, and 4F). Multiple oral administrations of EEA at $150 \mathrm{mg} / \mathrm{kg}$ significantly increased stool water content to $50.5 \pm 4.2$ (Figure 4F), but did not affect either the stool frequency or stool weight (Figure 4B and 4D). 


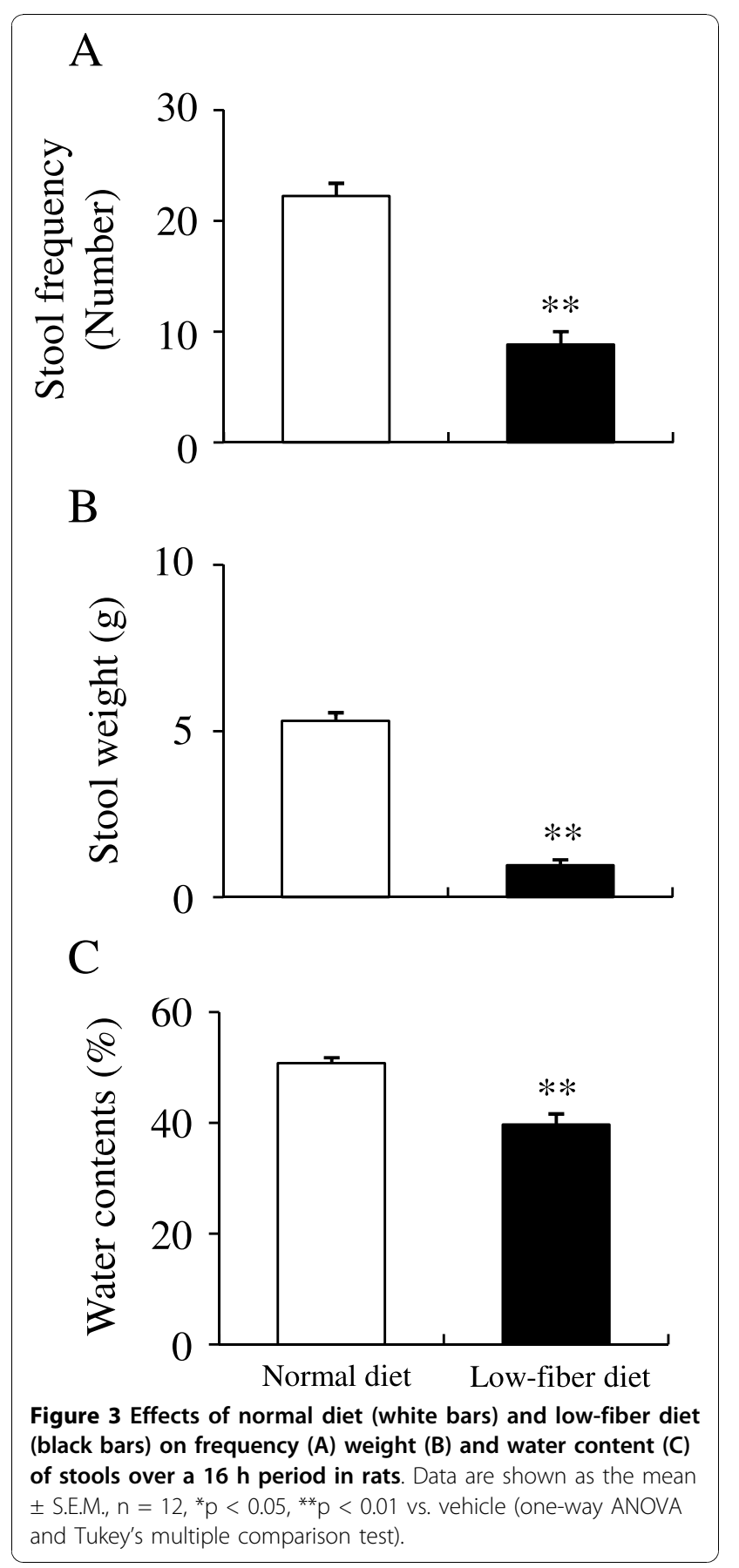

Multiple oral administrations of senna significantly increased the frequency, wet weight, and water content of stools to $13.3 \pm 5.5,3.59 \pm 1.77 \mathrm{~g}$, and $76.9 \pm 7.6 \%$, respectively, at $150 \mathrm{mg} / \mathrm{kg}$ and to $19.0 \pm 3.7,7.16 \pm 1.14$ $\mathrm{g}$, and $86.5 \pm 3.2 \%$, respectively, at $300 \mathrm{mg} / \mathrm{kg}$ (Figure $4 \mathrm{~B}, \mathrm{D}$, and 4F). Multiple oral administrations of EEA at 300 and $600 \mathrm{mg} / \mathrm{kg}$ and of senna at 150 and $300 \mathrm{mg} / \mathrm{kg}$ also significantly accelerated carmine egestion (Table 3B). Multiple oral administrations of senna at 150 and $300 \mathrm{mg} / \mathrm{kg}$ also induced diarrhea at the rates of 91.7 and $100 \%$, respectively (Table 4 ).

\section{Discussion}

In the rats fed normal diets, a single administration of EEA at $600 \mathrm{mg} / \mathrm{kg}$ significantly increased stool frequency and weight. EEA at 150 and $300 \mathrm{mg} / \mathrm{kg}$ showed a tendency to increase the frequency and weight of stools, but this difference was not statistically significant. Multiple oral administrations of EEA at 300 and 600 $\mathrm{mg} / \mathrm{kg}$ once daily for 14 days significantly increased stool frequency and weight. EEA at $300 \mathrm{mg} / \mathrm{kg}$ showed significant efficacy in normal mice at multiple administrations for 14 days, but was not effective as a single administration. These findings indicate that laxative effect of EEA on constipation is increased by dosage when supplied as a single administration and that multiple administrations of EEA do not induce tolerance.

Herbal medicines are now used by up to $50 \%$ of the Western population and they are used at least in part for the treatment or prevention of digestive disorders. Although most indications for the use of herbal medicines are anecdotally or traditionally derived, some of their efficacies have been scientifically demonstrated. Any herbal medicine may contain many bioactive compounds with potentially deleterious as well as beneficial effects [5]. Senna, a common herbal medicine, is frequently used as both an ethical pharmaceutical and as a proprietary drug. The deleterious effects of senna are severe diarrhea and abdominal cramping [5]. Therefore, senna is unsuitable for daily use.

Agarwood (Aquilaria sinensis etc.) is consumed as a traditional medicine (in the form of a tea) in regions of Southeast Asia, including Thailand, Taiwan, and Cambodia. Our previous report showed that an acetone

Table 2 Effects of low-fiber diet on the rate of carmine egestion in rats

\begin{tabular}{|c|c|c|c|c|c|c|c|c|c|c|}
\hline \multirow[b]{2}{*}{ Treatments } & & \multicolumn{9}{|c|}{ Number of rats egesting carmine-containing stools } \\
\hline & & $0-2$ & $2-4$ & $4-6$ & 6-8 & 8-10 & $10-12$ & $12-14$ & 14-16 & over $16 \mathrm{~h}$ \\
\hline Normal diet & & - & - & - & - & - & 5 & 4 & 3 & - \\
\hline Low-fiber diet & ** & - & - & - & - & - & - & - & - & 12 \\
\hline
\end{tabular}

Rats were maintained on a normal-diet or a low-fiber diet for 5 weeks. Carmine $(10 \mathrm{mg} / \mathrm{body})$ was orally administered to the rats, then the weights of carminecontaining-stools were measured during consecutive 2 -h periods over $16 \mathrm{~h}$. $n=12,{ }^{* *} \mathrm{p}<0.01$ vs. normal-diet (Chi-square test). 


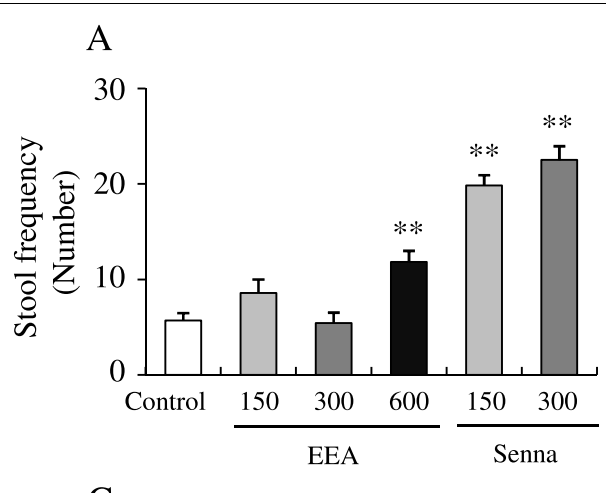

\section{B}
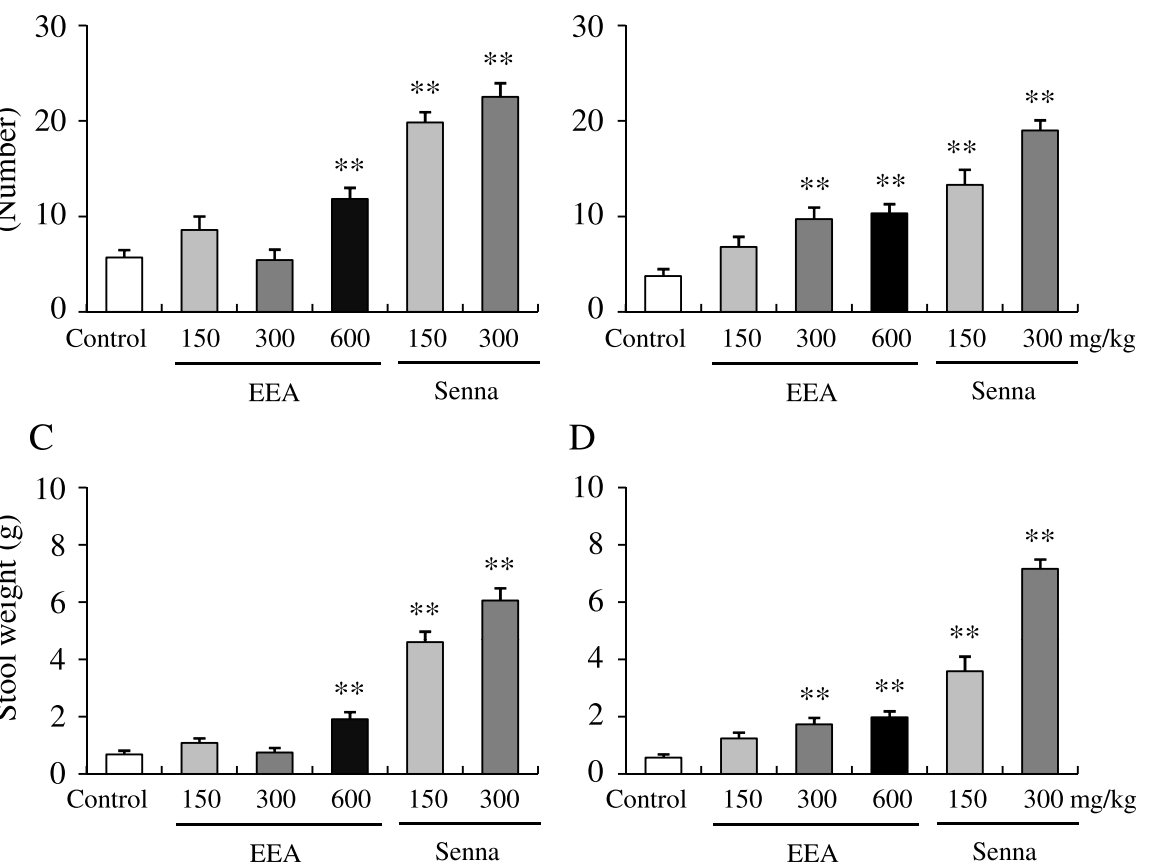

$\mathrm{D}$
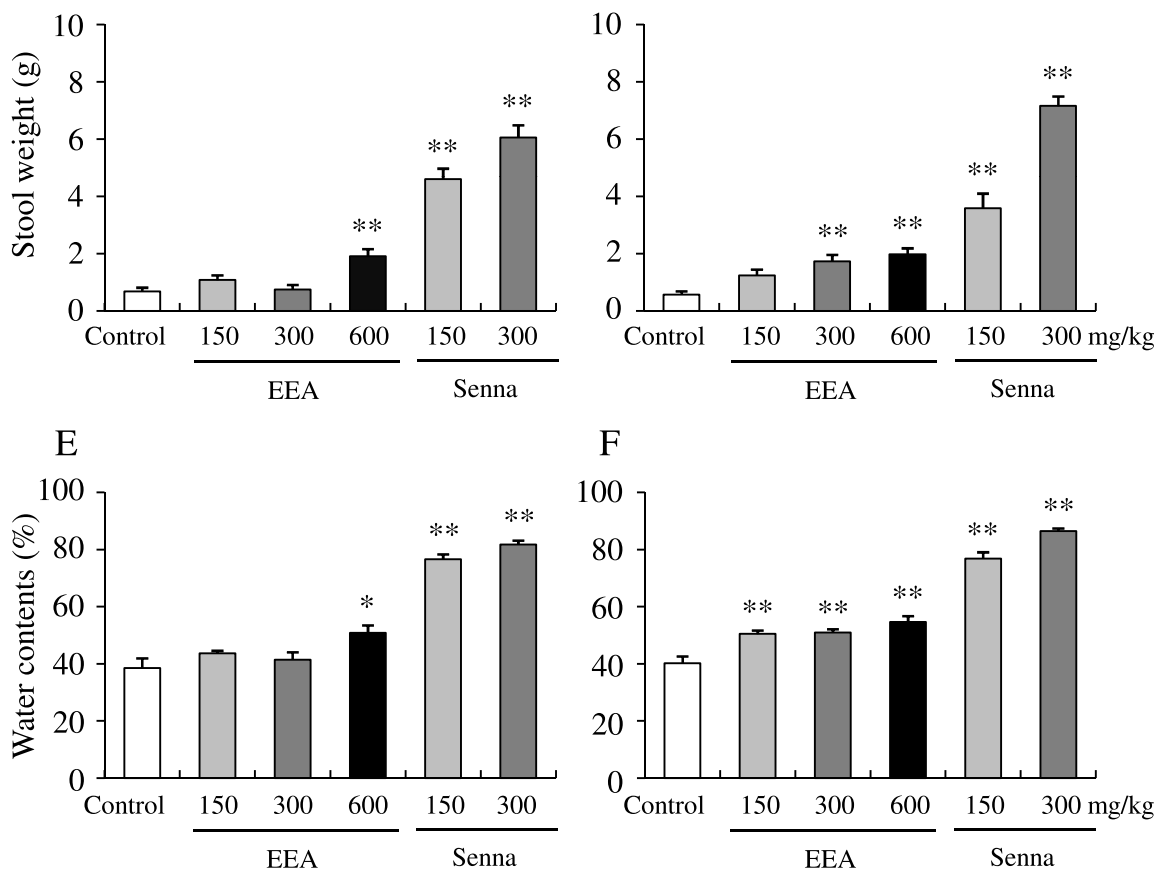

$\mathrm{F}$

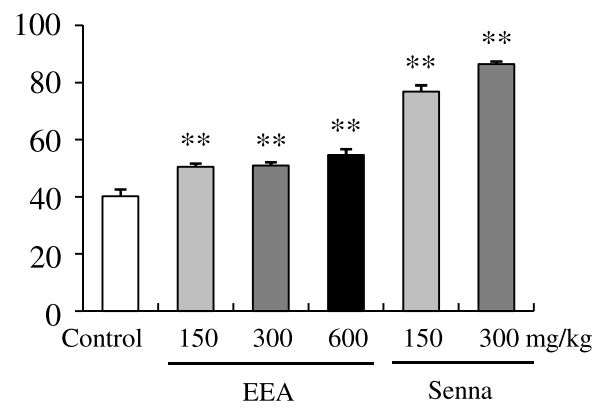

Figure 4 Effect of single ( $A, C$ and $E$ ) and 14-day (B, D and F) administrations of EEA and senna on stool frequency, weight and watercontent on rats with low fiber diet-induced constipation. Data are shown as the mean \pm S.E.M., $n=12,{ }^{* *} p<0.01,{ }^{*} p<0.05$ vS. vehicle (paired Tukey's multiple comparison test).

extract of agarwood had a laxative effect on normal mice and that the main pharmacologically active constituents of this extract is genkwanin-5-O-beta-primeveroside. When purified, genkwanin-5-O-beta-primeveroside increased the intestinal contractions of the ileum isolated from guinea pigs via action on acetylcholine receptors [6].

The actual botanical species called "agarwood" varies depending on region and is represented by more than fifteen different species [7]. In the previous study, we focused on two species (Aquilaria sinensis; from Taiwan, and Aquilaria crasna; from Thailand) and demonstrated that ethanol extracts of from either "agarwood" species had a laxative effect equal to that of the acetone extract of Aquilaria sinensis in a mouse model of loperamide-induced constipation [4]. We also demonstrated that an ethanol extract of Aquilaria sinensis increases both the intestinal tension of the small intestine and the rate of gastrointestinal transit.

In the present study, we demonstrated the laxative effects of EEA (Aquilaria sinensis) in a rat model of low-fiber diet-induced constipation. Maintaining a lowfiber diet for 5 weeks significantly decreased stool frequency, weight, and water content and significantly delayed carmine egestion. A single administration of EEA at $600 \mathrm{mg} / \mathrm{kg}$ significantly increased stool frequency, weight, and water content and significantly accelerated carmine egestion. Multiple administrations of EEA at 300 and $600 \mathrm{mg} / \mathrm{kg}$ also significantly increased the frequency and weight of stools, and at 
Table 3 Effects of EEA and senna on carmine egestion in a rat model of low-fiber diet-induced constipation

\begin{tabular}{|c|c|c|c|c|c|c|c|c|c|c|c|c|c|}
\hline \multicolumn{14}{|c|}{ A) Single administration } \\
\hline \multirow[b]{2}{*}{ Treatments } & \multirow[b]{2}{*}{$\mathrm{mg} / \mathrm{kg}$} & \multicolumn{12}{|c|}{ Number of rats egesting carmine-containing stools over $1 \mathrm{~g}$} \\
\hline & & $0-2$ & $2-4$ & 4-6 & $6-8$ & 8-10 & $10-12$ & $12-14$ & 14-16 & $16-18$ & $18-20$ & $20-22$ & $22-24 \mathrm{~h}$ \\
\hline Control & & - & - & - & - & - & - & - & 1 & - & 2 & 2 & 7 \\
\hline EEA & 150 & - & - & - & - & - & - & 2 & - & - & 1 & 5 & 4 \\
\hline EEA & 300 & - & - & - & - & - & - & - & 1 & 1 & 1 & 7 & 2 \\
\hline EEA & $600^{*}$ & - & - & - & - & - & 4 & 2 & 2 & 2 & - & 1 & 1 \\
\hline Senna & $150^{* *}$ & - & - & 5 & 3 & 3 & - & 1 & - & - & - & - & - \\
\hline Senna & $300^{* *}$ & - & 1 & 6 & 4 & 1 & - & - & - & - & - & - & - \\
\hline
\end{tabular}

B) Multiple administrations for 14 days

\begin{tabular}{|c|c|c|c|c|c|c|c|c|c|c|c|c|c|}
\hline \multirow[b]{2}{*}{ Treatments } & \multirow[b]{2}{*}{$\mathrm{mg} / \mathrm{kg}$} & \multicolumn{12}{|c|}{ Number of rats egesting carmine-containing stools over $1 \mathrm{~g}$} \\
\hline & & $0-2$ & $2-4$ & $4-6$ & $6-8$ & $8-10$ & $10-12$ & $12-14$ & $14-16$ & $16-18$ & $18-20$ & $20-22$ & $22-24 \mathrm{~h}$ \\
\hline Control & & - & - & - & - & - & - & - & - & 1 & - & 1 & 10 \\
\hline EEA & $300^{*}$ & - & - & - & - & - & - & - & 3 & 1 & 4 & - & 4 \\
\hline EEA & $600^{* *}$ & - & - & - & - & - & 1 & 2 & 2 & 3 & 3 & 1 & - \\
\hline Senna & $150^{* *}$ & - & - & 1 & 3 & 3 & 2 & 1 & - & - & - & 1 & 1 \\
\hline Senna & $300^{* *}$ & - & 5 & 5 & 2 & - & - & - & - & - & - & - & - \\
\hline
\end{tabular}

Low-fiber diet-induced constipation was induced in rats by feeding a low fiber diet for 5 weeks. EEA (150, 300, and $600 \mathrm{mg} / \mathrm{kg})$ and senna (150 and $300 \mathrm{mg} / \mathrm{kg})$ were orally administered daily for 14 days, and carmine (10 mg/body) was orally administered to rats just after the administration of the EEA or senna. Effects of single administration of EEA on carmine egestion (A). Effects of multiple oral administrations of EEA on carmine egestion (B). $n=12,{ }^{* *} p<0.01,{ }^{*} p<0.05$ vs. control (Chi-square test).

$150-600 \mathrm{mg} / \mathrm{kg}$, multiple administrations significantly increased stool water content and the rate of carmine egestion. A single treatment of EEA at 150 and $300 \mathrm{mg} /$ $\mathrm{kg}$ did not show efficacy, but repeated treatment of EEA at $300 \mathrm{mg} / \mathrm{kg}$ showed a significant increase in stool weight and stool frequency. These results indicate that EEA ameliorated low-fiber diet-induced constipation in rats; therefore, EEA may be suitable for human patients suffering from constipation due to their diet style.

Low-fiber diet-induced constipation relates to fecal consistency, because fecal consistency depends on the ratio of the water-holding capacity of the insoluble solids, such as dietary fibers. When there are sufficient water-holding solids and/or little non-bound (free)

Table 4 Effects of EEA and senna on diarrhea frequency

\begin{tabular}{lcccc}
\hline & & \multicolumn{3}{c}{ Frequency of diarrhea (\%) } \\
\cline { 3 - 5 } Treatments & $\begin{array}{c}\text { Dose } \\
\text { ( } \mathbf{m g} / \mathbf{k g})\end{array}$ & Day 1 & Day 7 & Day 14 \\
\hline Control & & 0 & 0 & 0 \\
EEA & 150 & 0 & 0 & 0 \\
EEA & 300 & 0 & 0 & 0 \\
EEA & 600 & 0 & 8.3 & 0 \\
Senna & 150 & 100 & 100 & 91.7 \\
Senna & 300 & 100 & 100 & 100 \\
\hline
\end{tabular}

EEA $(150,300$, and $600 \mathrm{mg} / \mathrm{kg})$ and senna $(150$ and $300 \mathrm{mg} / \mathrm{kg}$ ) were orally administered daily to constipated rats that had been maintained on a lowfiber diet for 5 weeks. EAA or senna were orally administered to the rats, then the frequency of diarrhea was measured over the next 16 h. $n=12$. water, stools remain thick or formed. On the other hand, if there are too few of these water-holding solids to bind all of the water present, stool consistency becomes loose, eventually to the point of being like water [8]. Repeated treatment of EEA at $150 \mathrm{mg} / \mathrm{kg}$ significantly improved the water contents, though failed to improve stool weight and stool frequency. This result indicates that compensation of water contents is not sufficient to show laxative activity in low-fiber dietinduced constipation.

Intestines of low-fiber diet-induced constipation animal are not inhibited by chemical constituents such as loperamide or clonidine. As our previous report showed, genkwanin-5-O-beta-primeveroside could play a key role in laxative activity via acetylcholine receptors in the presented low-fiber diet-induced model.

Laxative effect can also be exhibited by an increase in secretions in the GI tract, for e.g., like castor oil. This type of laxatives induce diarrhea, because secreted material liquefy stool consistency. EEA may have such effect, but its effect is not main mechanism of the laxative effect, because EEA does not induce the diarrhea.

EEA and senna both accelerated carmine egestion and these results indicate that EEA and senna shortened the preservation time of food in the digestive tract. On the other hand, in contrast to senna, orally administered EEA did not induce diarrhea, nor did it affect body weight (data not shown). Our previous report demonstrated that EEA increases contractions of the jejunum 
and ileum isolated from guinea pigs [7]. Collectively, these findings indicate that EEA may increase contractions of the intestine to accelerate food in the digestive tract without inhibiting nutrient absorption.

\section{Conclusions}

In conclusion, EEA, administered either in a single dose or multiple doses, showed a laxative effect on rats with low-fiber diet-induced constipation without causing the diarrhea typical of senna administration. These findings suggest that EEA may be useful as a therapeutic laxative agent in humans.

\section{List of abbreviation used}

EEA: Ethanol extract of agarwood leaves

\section{Acknowledgements}

The authors thank the late Kazumasa Yamaguchi in Nihon Bioresearch Inc. for technical assistance.

This work was financially supported by the Risk-taking Fund for Technology Development from the Japan Science and Technology Agency (Science Plaza, Tokyo).

\section{Author details}

${ }^{1}$ Molecular Pharmacology, Department of Biofunctional Evaluation, Gifu Pharmaceutical University, Gifu 501-1196, Japan. ${ }^{2}$ Nagara Research Center, API Co., Ltd., 692-3 Nagarayamasaki, Gifu 502-0071, Japan.

\section{Authors' contributions}

MK mainly performed the study, analyzed the data, and wrote the paper; ST supported the study, prepared the samples, and participated in the design of the study; HM, KT, YA, and MS participated in the design of the study and acquisition of the samples; $\mathrm{HH}$ conceived and organized the study, participated in the design of the study, and acquisition of the samples. All authors read and approved the final manuscript.

\section{Competing interests}

The agarwood leaves were supplied by API Co., Ltd. (Gifu, Japan). There is no other competing interest.

Received: 24 June 2010 Accepted: 15 November 2010

Published: 15 November 2010

\section{References}

1. Mostafa SM, Bhandari S, Ritchie G, Gratton N, Wenstone R: Constipation and its implications in the critically ill patient. Br J Anaesth 2003, 91:815-819.

2. Cooke WT: Laxative abuse. Acta Gastroenterol Belg 1981, 44:448-458.

3. Siegers $C P$, von Hertzberg-Lottin $E$, Otte M, Schneider B: Anthranoid laxative abuse-a risk for colorectal cancer? Gut 1993, 34:1099-1101.

4. Kakino M, Izuta H, Ito T, Tsuruma K, Araki Y, Shimazawa M, Oyama M, linuma $M$, Hara H: Agarwood induces laxative effects via acetylcholine receptors on loperamide-induced constipation in mice. Biosci Biotechnol Biochem , (accepted April 30, 2010).

5. Langmead L, Rampton DS: Herbal treatment in gastrointestinal and liver disease-benefits and dangers. Aliment Pharmacol Ther 2001, 15:1239-1252.

6. Hara H, Ise Y, Morimoto N, Shimazawa M, Ichihashi K, Ohyama M, linuma M Laxative Effect of Agarwood Leaves and Its Mechanism. Biosci Biotechnol Biochem 2008, 72:335-345.

7. Ng LT, Chang YS, Kadir AA: A review on agar (gaharu) producing Aquilaria species. Journal of Tropical Forest Products 1997, 2:272-285.

8. Saito T, Mizutani F, Iwanaga Y, Morikawa K, Kato H: Laxative and Antidiarrheal Activity of Polycarbophil in Mice and Rats. Japanese Journal of Phrmacology 2002, 89:133-141.
Pre-publication history

The pre-publication history for this paper can be accessed here: http://www.biomedcentral.com/1472-6882/10/68/prepub

doi:10.1186/1472-6882-10-68

Cite this article as: Kakino et al:: Laxative effects of agarwood on lowfiber diet-induced constipation in rats. BMC Complementary and

Alternative Medicine 2010 10:68.

\section{Submit your next manuscript to BioMed Central and take full advantage of:}

- Convenient online submission

- Thorough peer review

- No space constraints or color figure charges

- Immediate publication on acceptance

- Inclusion in PubMed, CAS, Scopus and Google Scholar

- Research which is freely available for redistribution

Submit your manuscript at www.biomedcentral.com/submit 